REVISTA DE LA CEPAL 88・ABRIL 2006

\section{Pacto Fiscal en Guatemala: lecciones de una negociación}

\author{
Juan Alberto Fuentes K. y Maynor Cabrera
}

$\mathrm{L}$

experiencia reciente de Guatemala con la negociación de un pacto fiscal, así como otros esfuerzos por alcanzar pactos sociales sobre la política fiscal, en algunas ocasiones con resultados satisfactorios y en otras no, dejan algunas lecciones o sugieren elementos clave de un pacto fiscal. En este artículo se analiza la experiencia guatemalteca a la luz de los principales factores determinantes de una serie de "pactos fiscales" exitosos o fracasados en países como Chile, Estados Unidos, la Federación de Rusia, Indonesia, Polonia, el Reino Unido y Suecia. El trabajo culmina con la identificación de diez claves para un pacto fiscal exitoso, tomando en cuenta tanto la experiencia de Guatemala como la de otros países.
Director,

Instituto Centroamericano

de Estudios Fiscales (ICEF)

• fuentesknight@yahoo.com

Maynor Cabrera

Consultor del Programa

de las Naciones Unidas

para el Desarrollo y de la Secretaría de

Planificación de Guatemala

•rmynorvc@yahoo.com 


\section{El marco institucional de la política fiscal guatemalteca antes del Pacto Fiscal del 2000}

A lo largo de la historia de Guatemala todos los gobiernos se han visto obligados a intentar reformas tributarias ante la permanente debilidad de las finanzas públicas. Pareciera que cada gobierno "descubre" esta debilidad e intenta resolverla sin comprender a cabalidad su naturaleza y los grandes desafíos que plantea. Estas iniciativas han enfrentado grupos de interés muy fuertes y bien organizados, reunidos en una confederación de cámaras empresariales, el Comité de Asociaciones Agrícolas, Comerciales, Industriales y Financieras (CACIF), generalmente con acceso directo al poder ejecutivo y con posibilidades de incidir fuertemente en la política tributaria. ${ }^{1}$ La relación directa -no mediada institucionalmente- entre el poder económico y el poder ejecutivo ha tomado dos formas: i) la de una negociación de elites que se ha reflejado en algunas reformas tributarias menores convenidas entre una elite tecnocrática y la elite empresarial o ii) la de confrontación, situación en la cual el sector privado ha recurrido a paros empresariales, movilización de la opinión pública a través de los medios de comunicación y la interposición de recursos de inconstitucionalidad para invalidar por la vía jurídica posibles aumentos de los impuestos.

Algunos artículos de la Constitución Política promulgada en 1985 debilitaron la posición de las autoridades fiscales y fortalecieron la de los contribuyentes. Por ejemplo, para impugnar resoluciones en materia tributaria no se debe exigir al contribuyente el pago previo del impuesto, y se prohíbe que las multas e intereses por mora superen el valor del impuesto omitido o en mora, por considerar la Constitución que esto es confiscatorio. Según la CEPAL, estas cláusulas reflejan el hecho de que en Guatemala se mezclan los derechos de propiedad con las obligaciones tributarias, lo cual no ocurre en otros países como El Salvador o Costa Rica. ${ }^{2}$ Además, la

\footnotetext{
${ }^{1}$ Véase McCleary (1999, p. 108), Valdez (2000, p. 12), Martí y Ortiz (1993), Valdez y Palencia (1998), Urrutia (2000) y Palencia (2002).

${ }^{2}$ Véase un análisis comparativo en CEPAL (1996).
}

Constitución prohíbe de manera muy vaga la doble tributación, lo cual ha dado lugar a múltiples interpretaciones de esta cláusula, con la consiguiente incertidumbre acerca de la aplicación o no de reformas tributarias aprobadas por el Congreso.

La Constitución también permite que cualquier ciudadano o empresa, con la asistencia de tres abogados, pueda presentar un recurso ante la Corte de Constitucionalidad — tribunal máximo en el ramo de la Constitución en Guatemala - la cual, si considera que la ley vulnera algún derecho constitucional, puede suspender su vigencia. Según la CEPAL esto fomenta que el campo de negociación de los impuestos sea una "negociación directa entre el Estado y las clases propietarias", mientras que en otros países como Costa Rica o El Salvador, es en el Congreso y en el terreno político donde se define el poder tributario del Estado (CEPAL, 1996).

Como consecuencia, la negociación sobre impuestos no se concentra principalmente en la aprobación de la legislación por el Congreso, ya que puede ser modificada con relativa facilidad por la Corte de Constitucionalidad ante la interposición de recursos de inconstitucionalidad. En este nuevo escenario los gobiernos pueden enfrentar una reducción de sus recursos financieros en el momento menos esperado, como sucedió en el año 1994, cuando la carga tributaria se redujo en $1 \%$ del PIB debido a que una ley tributaria fue declarada inconstitucional.

Un recuento de diversas iniciativas desde la década de 1980 hasta antes del 2000, año en que se firmó el Pacto Fiscal para un Futuro con Paz y Desarrollo, así como las respuestas del sector privado y el resultado final de la iniciativa se presenta en el cuadro 1. Tres conclusiones son evidentes. En primer lugar, predominaron las situaciones de confrontación, durante las cuales se confirmó el "poder de veto" del CACIF mediante paros empresariales, campañas de denuncia en los medios de comunicación y uso de recursos de inconstitucionalidad (lo que se dio independientemente del tipo de gobierno, fuese este militar o civil, con o sin mayoría en el Congreso). 
CUADRO 1

Guatemala: Resumen de reformas tributarias y sus resultados, 1980-1999

\begin{tabular}{|c|c|c|c|c|}
\hline $\begin{array}{l}\text { Gobierno y año } \\
\text { de reforma }\end{array}$ & $\begin{array}{l}\text { Propuestas del } \\
\text { gobierno }\end{array}$ & $\begin{array}{l}\text { Instrumentos de acción del } \\
\text { CACIF }\end{array}$ & Resultados & $\begin{array}{c}\text { Cambio en } \\
\text { carga tributaria }\end{array}$ \\
\hline \multicolumn{5}{|c|}{ Casos de confrontación } \\
\hline \multicolumn{5}{|c|}{ Régimen militar con conflicto armado interno } \\
\hline Ríos Montt (1983) & $\begin{array}{l}\text { Impuesto sobre la renta } \\
\text { (IVA) de } 10 \% \\
\text { Eliminación del impuesto } \\
\text { sobre exportaciones } \\
\text { Reglamento sobre } \\
\text { valoración aduanera } \\
\text { Impuesto a los bienes de } \\
\text { lujo }\end{array}$ & $\begin{array}{l}\text { Apoyo de la Cámara de } \\
\text { Comercio al IVA a cambio } \\
\text { de la no aprobación del } \\
\text { reglamento sobre } \\
\text { valoración aduanera y } \\
\text { del impuesto sobre } \\
\text { bienes de lujo } \\
\text { Campañas contra impuestos } \\
\text { en medios de comunicación }\end{array}$ & $\begin{array}{l}\text { Aprobación del IVA y } \\
\text { eliminación de impuestos a } \\
\text { las importaciones }\end{array}$ & $\begin{array}{c}-1,9 \% \\
\text { (entre } 1982 \text { y 1984) }\end{array}$ \\
\hline Mejía Victores (1985) & $\begin{array}{l}\text { Reducción del } \\
\text { IVA al } 7 \% \\
\text { Impuesto al café } \\
\text { Ampliación de la base del } \\
\text { IVA } \\
\text { Modificación al impuesto } \\
\text { sobre derivados del petróleo }\end{array}$ & $\begin{array}{l}\text { Oposición a medidas } \\
\text { Campañas contra el } \\
\text { gobierno en medios de } \\
\text { comunicación }\end{array}$ & $\begin{array}{l}\text { Derogación de leyes } \\
\text { Destitución de los ministros } \\
\text { de economía y de finanzas } \\
\text { públicas }\end{array}$ & $\begin{array}{c}1,7 \% \\
\text { (entre } 1984 \text { y } 1986)\end{array}$ \\
\hline \multicolumn{5}{|c|}{ Regímenes democráticos con conflicto armado interno } \\
\hline Vinicio Cerezo (1987) & $\begin{array}{l}\text { Impuesto temporal sobre } \\
\text { exportaciones } \\
\text { Modificaciones al impuesto } \\
\text { sobre la renta (ISR) } \\
\text { Modificaciones al IVA } \\
\text { Impuesto predial }\end{array}$ & $\begin{array}{l}\text { Oposición a medidas } \\
\text { mediante paro empresarial } \\
\text { y recursos de } \\
\text { inconstitucionalidad }\end{array}$ & $\begin{array}{l}\text { Impuesto temporal sobre } \\
\text { exportaciones no aprobado } \\
\text { Reformas al ISR, IVA e } \\
\text { impuesto predial declaradas } \\
\text { inconstitucionales }\end{array}$ & $\begin{array}{c}1,7 \% \\
\text { (entre } 1986 \text { y } 1988)\end{array}$ \\
\hline Ramiro de León (1994) & $\begin{array}{l}\text { Modificaciones al ISR } \\
\text { Igualación con países de } \\
\text { Centroamérica de tasas } \\
\text { sobre impuestos específicos } \\
\text { (bebidas, derivados del } \\
\text { petróleo, tabacos) } \\
\text { Aumento del IVA al } 10 \%\end{array}$ & $\begin{array}{l}\text { Oposición a medidas } \\
\text { mediante recursos de } \\
\text { inconstitucionalidad y } \\
\text { campañas contra el } \\
\text { gobierno en medios de } \\
\text { comunicación }\end{array}$ & Aumento del IVA (1996) & $\begin{array}{c}1,6 \% \\
\text { (entre 1993 y 1996) }\end{array}$ \\
\hline \multicolumn{5}{|c|}{ Casos de negociación de elites } \\
\hline \multicolumn{5}{|c|}{ Regímenes democráticos con conflicto armado } \\
\hline Jorge Serrano (1992) & $\begin{array}{l}\text { Reducción de tramos } \\
\text { marginales y techos del ISR } \\
\text { Simplificación del IVA } \\
\text { Acreditación del IVA } \\
\text { al ISR }\end{array}$ & $\begin{array}{l}\text { Negociación sin otras } \\
\text { acciones }\end{array}$ & Aprobación de reforma & $\begin{array}{c}0,5 \% \\
\text { (entre } 1991 \text { y } 1993 \text { ) }\end{array}$ \\
\hline \multicolumn{5}{|c|}{ Regímenes democráticos con Acuerdos de Paz } \\
\hline Alvaro Arzú (1996-1998) & $\begin{array}{l}\text { Reducción de tasa del ISR } \\
\text { Simplificación del IVA } \\
\text { Eliminación de } \\
\text { exoneraciones } \\
\text { Impuestos temporales sobre } \\
\text { ventas y activos (1996 y } \\
\text { 1998) }\end{array}$ & $\begin{array}{l}\text { Negociación sin otras } \\
\text { acciones }\end{array}$ & Aprobación de reforma & $\begin{array}{c}0,4 \% \\
\text { (entre } 1996 \text { y 1998) }\end{array}$ \\
\hline
\end{tabular}

Fuente: Elaboración propia sobre la base de Valdez y Palencia (1998), Urrutia (2000) y McCleary (1999) y datos del Ministerio de Finanzas Públicas. 


\section{Recuadro 1}

REFORMA FISCAL: ACTORES Y ESTILOS DE NEGOCIACIÓN COMO FACTORES DE ÉXITO

En Estados Unidos, el Reino Unido y Suecia el poder legislativo y los principales partidos políticos llegaron a acuerdos dentro de un marco claro y estable de reglas, el cual permitió que el cambio en la correlación de fuerzas diera lugar a nuevas políticas sin alterar las reglas básicas del juego, al tiempo que el marco institucional mediaba las iniciativas y fuerzas de las organizaciones empresariales y laborales, particularmente en Suecia y el Reino Unido. A su vez, el poder ejecutivo, con su sólida capacidad de recaudación y cierta autonomía de su tecnocracia, garantizaba la posibilidad de implementar adecuadamente las reformas.

En Chile hubo un proceso de consulta con sectores laborales y se tomó en cuenta la posición de la cúpula empresarial chilena en la formulación de las propuestas de reforma, pero estas se negociaron directamente entre la coalición de gobierno, la Concertación por la Democracia y el principal partido de oposición, Renovación Nacional (Boylan, 1996). A su vez, la capacidad recaudatoria del Ministerio de Hacienda y su independencia técnica y política no daban lugar a dudas sobre sus posibilidades de ejecutar las reformas sugeridas.

En Polonia el gobierno favoreció el desarrollo de negociaciones entre trabajadores y el Estado hasta culminar con lo que se convirtió en un pacto social que cubrió tanto el tema de los salarios — convenidos por la vía de una comisión tripartita de gerentes, gobierno y trabajadores- como el de la política tributaria, que luego fue ratificado por el organismo legislativo.

El gobierno ruso, en cambio, acudió a una negociación de elites, muy diferente a la negociación colectiva polaca. En particular, procedió a negociaciones informales con i) gobernadores regionales, dando lugar a acuerdos bilaterales sobre la proporción de ingresos para el gobierno central y los gobiernos locales; ii) gerentes de empresas estatales productoras de las materias primas exportadas, que eran las principales fuentes de ingresos, y iii) empresarios del sector financiero, que se convirtieron en las principales fuentes de crédito del gobierno así como en administradores de recursos del Estado. Estas negociaciones no dieron lugar a acuerdos duraderos.

Otra experiencia de reforma fiscal que en su momento fue considerada como un éxito fue la de Indonesia, aunque en este caso no existía un marco institucional democrático que mediara las presiones de diversos grupos, debido al carácter dictatorial del régimen de Suharto, jefe de Estado de Indonesia durante 30 años. Esto permitió que un grupo reducido de expertos nacionales, con asesoría internacional, estableciera un vasto conjunto de medidas que incluyeron la introducción del IVA, la simplificación y fortalecimiento del impuesto sobre la renta y la simplificación de otras leyes para facilitar la administración tributaria, pero que carecían de un apoyo político y social amplio.

En segundo lugar, cuando ha habido negociaciones estas han tomado la forma de "negociaciones de elites" entre una elite tecnocrática y la cúpula empresarial; el foro real de negociaciones no ha sido la institucionalidad democrática del país, ni el Congreso en particular. Finalmente, cuando ha habido negociaciones de elites, las propuestas que han logrado avanzar han sido aquellas tendientes a simplificar el sistema tributario o a aumentar el IVA y a erosionar la tributación directa, incluso mediante el establecimiento de impuestos temporales cuando han existido presiones para incrementarla. Como puede verse en el recuadro 1 , la incorporación de actores y los estilos de negociación han sido importantes en las experiencias internacionales.
Derivadas del escenario descrito, las características principales de la política fiscal en Guatemala antes de la suscripción del Pacto Fiscal en el 2000 habían sido, entre otras, las siguientes: bajos ingresos tributarios y reducidas asignaciones para el gasto social, deficiencias en la gestión de este - faltaban instrumentos técnicos para medir la calidad del gastoy una alta concentración del gasto en la región central del país. ${ }^{3}$ Lo anterior explica al menos en parte que Guatemala exhiba los indicadores sociales más rezagados en la región latinoamericana.

\footnotetext{
${ }^{3}$ Véase una descripción más detallada en SNU (2001, pp. 3-36 y 125-178).
} 


\section{II}

\section{La negociación del Pacto Fiscal en Guatemala}

\section{Factores condicionantes del surgimiento del Pacto Fiscal}

Luego de más de 30 años de conflicto armado interno y de un largo proceso de negociaciones, en 1996 se firmaron los Acuerdos de Paz en Guatemala. El fin de la guerra, así como los compromisos contenidos en dichos acuerdos, elevaron las expectativas de los ciudadanos y del propio gobierno, al constituirse en un pacto político de entendimiento mínimo para la construcción de un nuevo país. El Acuerdo sobre Aspectos Socioeconómicos y Situación Agraria (ASESA), uno de los más importantes del conjunto de Acuerdos de Paz, planteó la necesidad de que "antes del año 2000, la carga tributaria en relación al PIB se haya incrementado en por lo menos un $50 \%$ con respecto a la carga tributaria de 1995", para hacer posible el financiamiento de los programas y proyectos orientados a la consolidación del proceso de paz.

Entre los compromisos suscritos estaba el aumento del gasto público en educación y salud (como proporción del PIB) en un 50\% entre 1996 y el 2000, además de otras metas de aumento del gasto en vivienda y justicia, junto con una reducción moderada del gasto militar. Como parte de los compromisos, en los Acuerdos de Paz también se acordó que las Naciones Unidas serían responsables de verificar el cumplimiento de estas metas.

A fines de la década de 1990 la trayectoria de la recaudación tributaria indicaba que no se iba a pasar de una carga tributaria de aproximadamente $8 \%$ del PIB a mediados de la década de 1990 a la meta del 12\% en el año 2000. ${ }^{4}$ Reconociendo este hecho, el Gobierno de Guatemala promovió la modificación del calendario para alcanzar las metas establecidas en los Acuerdos de Paz, postergando hasta el 2002 la fecha en que debía alcanzarse la meta tributaria. Como parte de la

\footnotetext{
${ }^{4}$ Ante la revisión de las cuentas nacionales prevista en Guatemala estas proporciones de la carga tributaria $(8,10$ ó 12\%) pueden modificarse, pero esto no invalida el compromiso original del ASESA que estableció la necesidad de aumentar la carga tributaria en un 50\% a partir del nivel existente en 1996.
}

negociación para convenir esta modificación, el gobierno se comprometió a impulsar la aprobación de diversas leyes tributarias que incluían la creación de un impuesto sobre ventas y activos acreditable al impuesto sobre la renta, conocido como impuesto sobre empresas mercantiles y agropecuarias (IEMA); la reducción del grado en que se podía acreditar el IVA al impuesto sobre la renta; la reformulación del impuesto predial, y medidas para mejorar el cobro de los impuestos, como la contratación de compañías verificadoras de las transacciones del comercio exterior.

Sin embargo, a la postre lo que resultó más importante fue el compromiso adicional del gobierno de emprender un proceso encaminado a la suscripción de un "pacto fiscal" para promover una reforma tributaria concertada, crear una nueva cultura tributaria y fortalecer la capacidad de gestión de la política fiscal. ${ }^{5} \mathrm{La}$ idea de un pacto fiscal surgió en parte inspirada por el libro de la CEPAL con el mismo nombre (CEPAL, 1998), y principalmente como respuesta a una larga historia de reformas tributarias fracasadas e impulsadas en contextos de confrontación que incluyeron, como se explicó, la utilización de recursos de inconstitucionalidad para evitar la implementación de algunas reformas de impuestos, paros empresariales y campañas masivas en los medios de comunicación contrarias a las reformas tributarias propuestas.

Tras la idea de impulsar un pacto fiscal estaba el supuesto de que la reforma tributaria sólo sería sostenible si era consensuada -0 , en otras palabras, si el cumplimiento de las obligaciones tributarias era cuasi voluntario- y que de esa manera se la protegería de medidas de hecho de diversas fuerzas gremiales o políticas. Esto exigía una nueva institucionalidad, en la cual ninguna fuerza social tuviera la capacidad de ejercer un poder de veto, lo que sería congruente con la existencia de una verdadera democracia. ${ }^{6}$

\footnotetext{
${ }^{5}$ Sobre la relación entre el Pacto Fiscal y los Acuerdos de Paz en particular, véase Noriega, Alvarez y Chocoj (2001).

${ }^{6}$ Rosenthal (2005) destaca la importancia de esta condición en el contexto guatemalteco.
} 


\section{La negociación del Pacto Fiscal: un intento por crear un nuevo marco institucional}

\section{a) El Pacto Fiscal como acuerdo global}

El inicio de la concertación del Pacto Fiscal surgió por iniciativa de los integrantes de la comisión encargada de velar por el cumplimiento de los Acuerdos de Paz, conocida como la Comisión de Acompañamiento de los Acuerdos de Paz. Esta incluía a representantes del gobierno y del partido político de las antiguas fuerzas insurgentes, la Unidad Revolucionaria Nacional Guatemalteca (URNG), ciudadanos eminentes identificados como personas representativas de la sociedad civil, y las Naciones Unidas en calidad de observador.

Como primer paso, la Comisión de Acompañamiento formó una comisión encargada de elaborar, en consulta con distintos sectores de la sociedad guatemalteca y con base en estudios técnicos, una propuesta para la concertación del Pacto Fiscal, la cual se denominó Comisión Preparatoria del Pacto Fiscal (CPPF). Esta Comisión Preparatoria le dio credibilidad técnica y política al proceso, debido a que sus miembros, además de contar con un amplio acervo de conocimientos sobre la temática fiscal, conformaban un grupo plural, representaban las visiones que sobre el tema fiscal se daban en Guatemala y algunos tenían una relación estrecha con los partidos políticos más importantes en ese momento. ${ }^{7}$

El proceso preparatorio del Pacto Fiscal se llevó a cabo en un año electoral. A pesar de ello se realizó una serie intensiva de consultas con distintos sectores (académico, privado, sindical, cooperativo y de partidos políticos) de todo el país, los medios de comunicación le dieron una amplia y positiva cobertura al tema; asimismo, se contó con un sólido apoyo técnico de la cooperación internacional, ${ }^{8}$ que al extenderse a diversas organizaciones académicas y sociales permitió que el tema se conociera y debatiera ampliamente ese año. Lo anterior culminó con la propuesta de Pacto Fiscal, presentada públicamente por la Comisión Preparatoria el 29 de diciembre de 1999. Esta propuesta tenía dos características: i) su enfoque era integral, ya que se refería no sólo a una reforma tributaria sino al conjunto de las finanzas públicas: gasto público, administración tributaria, deuda, déficit, patrimonio público, transparencia y descentralización, y ii) estaba

\footnotetext{
${ }^{7}$ Según Gamboa y Tentravizi (2000, pp. 53-72), la composición de la CPPF era bastante equilibrada porque los miembros representaban un balance entre las posiciones de izquierda y derecha moderada, los principales asesores económicos del partido oficialista y la primera fuerza de oposición.

${ }^{8}$ En Comisión Preparatoria del Pacto Fiscal (2000) aparecen estudios que sirvieron para elaborar la propuesta del Pacto Fiscal.
}

orientada hacia principios y compromisos, con visión de mediano y largo plazo, en vez de centrarse exclusivamente en medidas de corto plazo.

En febrero del 2000, la Comisión de Acompañamiento lanzó la convocatoria a la consulta sobre la propuesta elaborada por la Comisión Preparatoria, haciéndola llegar a cerca de 150 organizaciones e instituciones de distinto tipo: sindicatos, pequeños y medianos empresarios, cámaras empresariales, cooperativas, iglesias, organizaciones no gubernamentales, organizaciones campesinas, indígenas y de mujeres, universidades y centros de investigación. Como respuesta hubo 48 propuestas en representación de 131 organizaciones. Con base en dichas propuestas, un equipo técnico nombrado por la Comisión de Acompañamiento identificó los principales consensos y disensos. Partiendo de los últimos, la Comisión de Acompañamiento procedió a realizar un trabajo de cabildeo para acercar posiciones entre el sector empresarial organizado y las organizaciones sociales, que después de un período de diálogo y negociación se fueron perfilando en dos posiciones diferentes respecto a varios temas.

Luego del trabajo de cabildeo y de la realización de un foro con las organizaciones que enviaron propuestas, constituido como Foro Nacional del Pacto Fiscal, fue posible llegar a los acuerdos finales y a la firma del Pacto Fiscal por más de 100 organizaciones, además de los presidentes de los tres poderes del Estado. En general, y si bien hubo una negociación seria sobre algunos temas neurálgicos como la progresividad de la tributación y el uso de recursos derivados de privatizaciones y reformas constitucionales, se respetó la mayor parte de las propuestas hechas originalmente por la Comisión Preparatoria y se mantuvo la misma estructura basada en el establecimiento de principios y compromisos para el conjunto de temas de las finanzas públicas.

Gamboa y Tentravizi (2001, pp. 131-139) señalan que factores como las características de la Comisión Preparatoria (representatividad y alto nivel técnico), la identificación de principios y compromisos orientados al mediano y largo plazo en vez de discutir medidas tributarias, y la existencia de un documento único como base del debate fueron muy importantes para que el Pacto Fiscal culminara con un acuerdo sobre un tema que en el pasado había sido objeto de múltiples divergencias. A lo anterior podría agregarse el marco favorable dado por los Acuerdos de Paz, la unidad de las organizaciones sociales, que en cierta medida constituyeron un contrapeso al CACIF, un método de negociación flexible que aprovechaba la experiencia de negociación de los Acuerdos de Paz y un 
aprendizaje colectivo que dio cierta flexibilidad o fluidez a las posiciones de los participantes, facilitando una convergencia entre ellos. En la práctica esto representaba el ingreso de nuevos actores para incidir en un tema que tradicionalmente había estado sujeto a negociaciones de un grupo pequeño de altos funcionarios gubernamentales y representantes del sector privado.

Durante esta etapa preparatoria y de negociación, los dos gobiernos de turno (el de 1996-1999 y el de 2000-2003) dieron un importante apoyo a la formulación y discusión del Pacto Fiscal, aunque sin tener un protagonismo marcado. Por su parte, el sector empresarial estuvo de acuerdo con este proceso, lo cual se ha atribuido en parte a temor al Frente Republicano Guatemalteco (FRG). Este partido político había ganado las elecciones en 1999 con un discurso populista y antiempresarial, por lo que desde la perspectiva de los empresarios el Pacto Fiscal podía ser útil para definir un marco de reglas con cierta estabilidad y transparencia que pudiera regir la actuación del nuevo gobierno y sus relaciones con otros sectores (Segovia, 2004, p. 64).

Esto puede interpretarse como el cambio en la correlación de fuerzas que en otras circunstancias ha favorecido la negociación de pactos fiscales, como se señala en el recuadro 2. Hay que reconocer, sin embargo, que la misma perspectiva de un cambio de gobierno cada cuatro años y la necesidad de cierta estabilidad y de una visión compartida de nación, ${ }^{9}$ también pueden haber sido un aliciente para considerar de manera positiva el esfuerzo de acordar un Pacto Fiscal, posición que ya era manifiesta meses antes de las elecciones en que ganó el FRG. ${ }^{10}$

Recuadro 2

El CAMBIO EN LA CORRELACIÓN DE FUERZAS COMO REQUISITO DE UN NUEVO PACTO FISCAL

En los países desarrollados, el sistema impositivo cuasi voluntario ha estado sujeto a renegociaciones, dando lugar a ajustes de los pactos sociales que sustentan la política fiscal y que se han reflejado en renovaciones o nuevos pactos fiscales. Así, sin que se cuestionara la institucionalidad básica y las ventajas de contar con un sistema impositivo cuasi voluntario, ha habido en la historia de esos países, lo que se puede interpretar como nuevos o renovados pactos fiscales, como lo ilustran Suecia en 1938, el Reino Unido entre 1939 y 1941 y Estados Unidos en 1986 (Steinmo, 1993).

Todos ellos fueron desencadenados por un hecho especial que alteró la correlación interna o externa de fuerzas: i) la victoria del partido social demócrata en las elecciones suecas en 1936, que dio lugar a un pacto negociado entre el sector empresarial y el laboral, el cual fue la base del llamado "modelo sueco" que se consolidó posteriormente; ii) la segunda guerra mundial en el caso del Reino Unido, que requirió un esfuerzo especial de movilización de recursos para financiar la industria militar, y iii) la victoria electoral de Ronald Reagan combinada con la denuncia comprobada de una reducida carga tributaria de grandes empresas en los Estados Unidos entre 1981 y 1986.

Chile, país en desarrollo pero con un pacto fiscal exitoso a partir de 1990, ilustra con claridad cómo la política fiscal está asociada al fortalecimiento de la democracia y cómo una nueva correlación de fuerzas contribuye a ese fortalecimiento y a la reforma fiscal, dándose una retroalimentación positiva entre ambos procesos. El detonante de la iniciativa fue el establecimiento de una nueva correlación de fuerzas internas, puesta de manifiesto inicialmente con el rechazo a la dictadura militar en el plebiscito de 1988 y ratificado en las elecciones de 1989 con un triunfo de las fuerzas de centro-izquierda agrupadas en la Concertación por la Democracia (demócratacristianos, socialistas y otros). Esto, unido a un creciente déficit fiscal y a promesas de reducir la deuda social, condujo a la negociación de una reforma dentro de un marco institucional aún incipiente, con un poder legislativo condicionado por restricciones impuestas por el gobierno militar, ${ }^{11}$ pero con partidos políticos institucionalmente sólidos que fueron el eje de la negociación de la reforma tributaria.

En Polonia, donde también se acordó un nuevo pacto fiscal, se inició en 1989 una transición con un gobierno apoyado por el Movimiento Solidaridad, pero con un poder legislativo que, debido al resultado de las elecciones de 1991, estaba fragmentado y virtualmente paralizado. ${ }^{12}$ En este contexto de fluidez del marco institucional hubo un cambio en la correlación de fuerzas a favor de los trabajadores (de la industria, del campo y del sector público), los que recurrieron inicialmente a acciones de protesta —incluyendo huelgas_ ante las medidas radicales de reforma económica introducidas por el nuevo gobierno y en oposición a un impuesto aplicado a salarios por encima de cierto monto (el popiwek).

\footnotetext{
${ }^{9}$ Palencia (2002, pp. 79-87 y p. 63). Sobre este tema véase también Valdez (2003).

${ }^{10}$ Aunque en la medida en que existieran expectativas ("racionales") de la victoria del FRG, ya se estaban internalizando o procesando como parte del futuro cercano.
}

\footnotetext{
${ }^{11}$ El Senado incluía en ese momento nueve senadores designados por el régimen militar, por lo que los votos del partido Renovación Nacional eran decisivos para lograr la mayoría simple en esta instancia.

${ }^{12}$ Lo que sigue está basado en Easter (2002).
} 
Por otra parte, la concertación del acuerdo amplio sobre el Pacto Fiscal incluyó al partido político URNG y a una serie de organizaciones sociales y sindicales que hicieron propuestas sobre el tema, aprovechando el apoyo discreto y no protagónico de la cooperación internacional. En su conjunto, la comunidad internacional apoyó el proceso de negociación, destacando la importancia de cumplir con la meta tributaria del $12 \%$ establecida en los Acuerdos de Paz, aunque las instituciones financieras internacionales no dejaron de expresar cierta reserva ante la posibilidad de que el proceso pudiera ser una excusa para que el gobierno no cumpliera con el compromiso de aumentar la carga tributaria. En consecuencia, estas instituciones dieron algún apoyo técnico pero guardaron su distancia, lo cual favoreció el proceso al asegurar una verdadera "apropiación" nacional del mismo. Otras fuentes de cooperación contribuyeron a que actores de la sociedad civil —organizaciones sociales y académicas- pudieran realizar estudios y hacer propuestas, reduciendo la histórica asimetría que había caracterizado el manejo de la política fiscal, restringido a actores gubernamentales y empresariales en el pasado.

Aunque la Comisión Preparatoria había consultado a los partidos políticos durante la etapa de preparación de su propuesta, y a pesar de que los partidos incluyeron en sus programas electorales de gobierno el apoyo genérico a la idea de constituir un Pacto Fiscal, no todos los partidos —en particular el Partido de Avanzada Nacional (PAN) del anterior gobierno, que posteriormente pasó a la oposición- lo apoyaron después de su negociación final. Dentro de los partidos políticos nunca dejó de existir cierto temor al costo político asociado a los impuestos, sin querer aceptar o entender el argumento de que el pacto permitía que este costo se compartiera entre todos.

En esa actitud incidió la conocida precariedad del sistema de partidos políticos en Guatemala, caracterizados por su fragmentación, tendencia caudillista, inconsistencia y limitada durabilidad. Además, en la etapa de negociación del Pacto Fiscal hubo una falla fundamental de estrategia, pues no se aseguró una efectiva participación institucional del Congreso recién electo - aunque sí de diputados individuales, incluyendo a la que presidió la Comisión de Finanzas del Congreso-,${ }^{13}$ lo cual ya anunciaba lo que fue quizás

${ }^{13}$ En la Comisión de Acompañamiento estaba representado el Congreso, pero eso no fue suficiente para asegurar una sólida articulación con el poder legislativo en su conjunto. la principal debilidad del nuevo marco institucional para llevar el Pacto Fiscal a la práctica.

\section{b) El fracaso de la negociación del componente tributario del Pacto Fiscal}

La naturaleza más general de los principios y compromisos contenidos en el acuerdo global sobre el Pacto Fiscal permitieron que diferentes visiones gremiales y sectoriales convergieran con menos dificultad al discutir medidas concretas y, sobre todo, la aprobación o modificación de impuestos. En la subsiguiente negociación de la reforma tributaria, auspiciada por la Comisión de Acompañamiento, participaron las organizaciones sociales agrupadas en el Colectivo de Organizaciones Sociales (cos), el sector empresarial organizado cuya representación la tenía el Comité de Asociaciones Agrícolas, Comerciales, Industriales y Financieras (CACIF) y los principales centros de investigación: el Centro de Investigaciones Económicas Nacionales (CIEN) y la Asociación de Investigación y Estudios Sociales (ASIES). Actuó como moderadora la Comisión de Acompañamiento y prestó un activo apoyo técnico y de facilitación la Misión de las Naciones Unidas en Guatemala (MINUGUA).

Sin embargo, hubo dos problemas que minaron este proceso de negociación. En primer lugar, hubo una participación poco protagónica del Ministerio de Finanzas en las negociaciones, en parte por aparentes divergencias dentro del gobierno, entre ellas una posición que no favorecía tomar parte en este proceso por estimar que le aseguraba demasiado protagonismo al CACIF y le negaba al gobierno la legitimidad que había ganado en las elecciones. En la práctica, la extrema debilidad del poder ejecutivo, reflejado en su incapacidad de coordinar posiciones sobre el tema, impidió que se consolidara el nuevo marco institucional que se estaba conformando y fue una de las causas del fracaso de esta iniciativa. La negociación fue más compleja en esta ocasión, con divergencias sobre la importancia relativa que debían tener los impuestos directos o indirectos y sobre las exenciones que debían eliminarse,${ }^{14}$ dando lugar a posiciones extremas y demoras que no permitieron presentar lo acordado oportunamente al Congreso. Con todo, se pudo convenir el Acuerdo

\footnotetext{
${ }^{14}$ Para los sectores sociales el punto crítico fue el aumento del IVA, lo que incluso después causó divisiones internas. La negociación del IVA se condicionó al aumento de los salarios mínimos. Para el sector privado, la negociación de los privilegios fiscales y la tributación directa fue el tema de mayor contradicción con los sectores sociales (véase Palencia, 2002).
} 
Político para el Financiamiento de la Paz, el Desarrollo y la Democracia, con medidas concretas para alcanzar la meta de carga tributaria del $12 \% .{ }^{15}$

En segundo lugar, a la incapacidad del poder ejecutivo de coordinar posiciones se sumó el hecho de que el partido mayoritario en el Congreso (el FRG) no acogió con beneplácito la nueva propuesta que se había convenido, argumentando que los diputados no habían participado en el proceso previo de negociaciones y poniendo de manifiesto en este caso las limitaciones del Congreso como ente mediador y de negociación al más alto nivel político. ${ }^{16}$ Paradójicamente el organismo legislativo, y especialmente su presidente, el general Ríos Montt, desaprovechó la oportunidad de aprobar una reforma tributaria significativa sin mayores costos políticos, con aumentos de las tasas del impuesto sobre la renta y del IVA ya aprobados por el sector privado y por las organizaciones sociales más importantes del país. Había existido la posibilidad de llegar a un genuino Pacto Fiscal, pero se perdió la oportunidad de lograrlo.

\section{c) El retorno al viejo marco institucional}

i) El retorno a la confrontación. La estrategia del gobierno y del partido oficialista fue entonces la de convocar a nuevas negociaciones bajo la dirección del vicepresidente de la república. Estas fueron un fracaso e incluso condujeron a un repliegue en ciertas posiciones, principalmente por el lado de las organizaciones sociales, que entonces rechazaron el aumento del IVA. Ese año 2000, el Congreso, con el apoyo de la mayoría de diputados del partido oficialista, aprobó parte de las reformas incluidas en el Acuerdo Político, sin incluir el aumento del IVA. Esto se hizo en un clima de creciente confrontación con el sector privado y

\footnotetext{
${ }^{15}$ En resumen lo convenido - llamado Acuerdo Político- incluía: i) el fortalecimiento de la administración tributaria y medidas para combatir la evasión y el contrabando; ii) la revisión de deducciones y exoneraciones vigentes; iii) el incremento del IVA del 10\% al 12\%; iv) el alza de la tasa máxima del impuesto sobre la renta del $25 \%$ al $31 \%$; v) otras medidas tributarias, que incluían un aumento del impuesto de salida del país, un nuevo impuesto sobre las bebidas alcohólicas, una nueva ley de impuesto sobre bienes inmuebles y una modificación para hacer permanente un impuesto sobre activos que originalmente era temporal; vi) un incremento de los salarios mínimos; vii) la puesta en marcha de un programa de reactivación económica, y viii) la implementación de un programa de gasto público prioritario.

${ }^{16} \mathrm{Al}$ mismo tiempo que la Comisión de Acompañamiento presentaba al Congreso el Acuerdo Político, el Ministerio de Finanzas presentaba otra propuesta que excluía el IVA e incluía un impuesto sobre transacciones financieras, con lo que se hizo más compleja la negociación de las reformas propuestas.
}

sin el apoyo de las organizaciones sociales y de los partidos de oposición en el Congreso.

Con posterioridad a la aprobación de las leyes tributarias, y ante la insuficiencia de las medidas aplicadas, persistió la amenaza de la aprobación del IVA, sujeta a divergencias entre el Congreso y el Ejecutivo. Cuando empezaron a surgir cuestionamientos al gobierno desde el sector privado, medios de comunicación y organizaciones sociales, ${ }^{17}$ la estrategia gubernamental fue replanteada. Se cambió el Ministro de Finanzas Públicas y el gobierno impulsó dos medidas: un incremento del IVA del $10 \%$ al $12 \%$, propuesto en el Acuerdo Político negociado previamente, y un aumento de las tasas del impuesto a las empresas mercantiles y agropecuarias (IEMA). El ambiente general de creciente polarización favoreció que las organizaciones sociales y del sector privado, así como los partidos no oficialistas, se opusieran firmemente a estas medidas.

Si bien la firma del Pacto Fiscal fue un punto culminante en la historia de la concertación en Guatemala, el alza de las tasas del IVA y del IEMA, en el 2001, marcó uno de los puntos más bajos, por el grado de confrontación existente. Esta asumió diferentes formas: manifestaciones populares de las organizaciones sociales, campañas de los medios de comunicación en contra del gobierno, paro empresarial en el sector priva$\mathrm{do}^{18}$ y algunas campañas de protesta ciudadana, en las cuales los ciudadanos vistieron de negro, principalmente como rechazo al incremento del IVA y a las denuncias de corrupción en el gobierno. También aumentó fuertemente la interposición de recursos de inconstitucionalidad, que no habían tenido lugar el año 2000 cuando se suscribió el Pacto Fiscal, lo que demuestra la credibilidad que tuvo la negociación de ese pacto. En el 2001, en cambio, fueron interpuestos 41 recursos de inconstitucionalidad (31 por el sector empresarial, tres por partidos políticos y los restantes por la sociedad civil); en el 2002 fueron interpuestos nueve (cinco por el sector empresarial y cuatro por la sociedad civil) y en el 2003 fueron interpuestos 11 (seis por el sector empresarial y cinco por la sociedad civil).

ii) El retorno a la negociación (ampliada) de elites. Tras la victoria de la Gran Alianza Nacional (GANA) en las elecciones generales del 2003, el nuevo gobierno asumió una orientación pro-empresarial.

\footnotetext{
${ }^{17}$ Principalmente por el conocimiento sobre actos de corrupción y la débil gestión pública.

${ }^{18}$ En este caso, las manifestaciones de inconformidad del sector privado sobre el aumento del IVA estaban fundamentadas en su rechazo a la gestión del gobierno de turno, no al impuesto en sí.
} 
Paradójicamente, la persistente interposición de recursos de inconstitucionalidad por el sector privado en años previos generó una pérdida de ingresos tributarios al nuevo gobierno cuya gestión se inició en el 2004, especialmente por la declaración de inconstitucionalidad del impuesto aplicado a activos y ventas (el IEMA). Por lo tanto, durante los primeros meses del nuevo gobierno se decidió que era necesario retomar el Pacto Fiscal como medida para enfrentar la crisis. Con este propósito el poder ejecutivo formó una Comisión Técnica del Pacto Fiscal (CTPF), ${ }^{19}$ a la cual se le encomendó elaborar un proyecto de reforma tributaria.

En este caso el proceso de consulta estuvo bastante acotado. Por una parte, la cercana relación entre la Comisión Técnica y altos funcionarios del gobierno vinculados a la política fiscal, dada la orientación pro-empresarial del gobierno, contribuyeron a que las principales inquietudes empresariales fueran tomadas en cuenta. Por otra, el mandato técnico de la Comisión propició un proceso acelerado y tardío de consultas con otros sectores y sin un proceso previo de consultas con los partidos representados en el Congreso. En todo caso, la propuesta de la Comisión Técnica finalmente fue presentada a la Comisión Nacional de los Acuerdos de Paz (CNAP), ${ }^{20}$ y enviada por esta al Congreso de la República con pequeños cambios.

Diversos sectores argumentaron que la consulta para elaborar la propuesta fue insuficiente como para poder traducirse en un "pacto fiscal". No obstante, el Congreso de la República llevó adelante un proceso de consultas adicional bajo la modalidad de "audiencias públicas". Este mecanismo de participación democrática, que había permanecido ajeno a Guatemala, permitió escuchar las opiniones de distintas agrupaciones sociales, académicas, empresariales e indígenas. Las audiencias públicas, que no se habían efectuado hacía 50 años en el país, lograron que al menos transitoriamente el debate fiscal contribuyera a oxigenar la democracia guatemalteca y a ir más allá de la confrontación o de la negociación de elites.

En la práctica el Congreso, que de nuevo no había sido tomado en cuenta en el proceso de formulación de la propuesta de reforma tributaria y no contaba con asesoría especializada en materia tributaria, debilitó aún más las propuestas hechas por la Comisión Técnica. En ello incidieron en parte reivindicaciones de organizaciones sociales — que tampoco fueron

\footnotetext{
${ }^{19}$ La cual sustituyó a la Comisión de Seguimiento del Pacto Fiscal ${ }^{20}$ Este organismo sustituyó a la Comisión de Acompañamiento de los Acuerdos de Paz (CAAP).
}

incorporadas a un proceso amplio de consulta- y cuyas posiciones reflejaban intereses urbanos de clase media que coincidían con el interés del sector privado de no tener un impuesto sobre la renta más alto.

Las reformas a las leyes tributarias sólo fueron aprobadas una vez que existió un entendimiento entre las diferentes bancadas del Congreso. Las iniciativas aprobadas fueron cuatro: i) modificaciones al impuesto sobre la renta, por las cuales se creaba un régimen simplificado de pago del 5\% sobre los ingresos brutos como alternativa al régimen del $31 \%$; ii) la creación del impuesto extraordinario y temporal de apoyo a los Acuerdos de Paz (IETAAP), un gravamen sobre activos y ventas con características similares a las del IEMA, pero con tasas menores y de carácter temporal, congruente con las posiciones del CACIF; iii) un impuesto sobre bebidas alcohólicas, que no estaba vigente por haber sido declarado inconstitucional y iv) la autorización para acrecentar el endeudamiento del gobierno central.

Cabe destacar dos características de esta reforma. Primero, introdujo modificaciones menores que reflejaban la existencia de una negociación de elites entre el gobierno y el CACIF, con un débil papel de mediación del poder legislativo, habiéndose acordado medidas de simplificación o de poco impacto, con un componente temporal en materia de tributación directa, todo lo cual era congruente con la visión tradicional del sector privado guatemalteco sobre los impuestos. Segundo, la aprobación incompleta de las reformas solamente generó recursos por la mitad de lo previsto en la reforma inicial. Es más, la reforma finalmente aprobada fue insuficiente para restituir los ingresos perdidos por los recursos de inconstitucionalidad, por lo que la carga tributaria se mantuvo en $10,3 \%$ en el año 2004, equivalente al nivel del 2003 pero inferior al del $2002(10,6 \%)$. Cuando se analiza la política fiscal de manera integral hay que reconocer otros avances, entre ellos un fortalecimiento (reciente) de la administración tributaria ${ }^{21}$ y un mayor grado de transparencia del gasto público. Sin embargo, continúa sin resolverse el problema mayor y más arduo: la insuficiencia de ingresos tributarios.

\footnotetext{
${ }^{21}$ Por otro lado, a pesar de que la Superintendencia de Administración Tributaria (SAT) fue concebida como una entidad autónoma y de carácter técnico, el cambio continuo de autoridades (cinco superintendentes en ocho años de existencia) no le ha permitido desarrollar políticas de largo plazo. Además, la transparencia de la entidad se vio afectada fuertemente en el año 2003, cuando fue nombrado director de esta entidad el antiguo Contralor de Cuentas, posteriormente sujeto a un juicio por enriquecimiento ilícito.
} 
CUADRO 2

Guatemala: Reformas tributarias y sus resultados después del Acuerdo sobre el Pacto Fiscal, 2000-2004

\begin{tabular}{|c|c|c|c|c|}
\hline $\begin{array}{l}\text { Gobierno y año } \\
\text { de reforma }\end{array}$ & $\begin{array}{l}\text { Propuestas de } \\
\text { gobierno }\end{array}$ & Instrumentos de acción & Resultados & $\begin{array}{c}\text { Cambio en } \\
\text { carga tributaria }\end{array}$ \\
\hline \multicolumn{5}{|c|}{ Casos de confrontación } \\
\hline Alfonso Portillo (2000) & $\begin{array}{l}\text { Incremento del IVA }{ }^{\mathrm{a}} \text { al } 12 \% \\
\text { Incremento del ISR } \\
\text { Reducción de la acredita- } \\
\text { ción del IVA al ISR } \\
\text { Eliminación de } \\
\text { exoneraciones y } \\
\text { deducciones } \\
\text { Modificación de impuestos } \\
\text { específicos (tabacos, } \\
\text { cemento, bebidas) }\end{array}$ & $\begin{array}{l}\text { Negociación, salvo respecto } \\
\text { de los impuestos sobre } \\
\text { bebidas alcohólicas, que se } \\
\text { enfrentaron con recursos de } \\
\text { inconstitucionalidad }\end{array}$ & $\begin{array}{l}\text { Aprobación de reformas } \\
\text { sobre exoneraciones y } \\
\text { deducciones e impuestos } \\
\text { específicos } \\
\text { Incremento del ISR }\end{array}$ & $\begin{array}{c}0,4 \% \\
\text { (entre } 1999 \text { y 2001) }\end{array}$ \\
\hline Alfonso Portillo (2001) & $\begin{array}{l}\text { Incremento de la tasa del } \\
\text { IVA al } 12 \% \\
\text { Incremento de la tasa del } \\
\text { IEMA }^{\text {c }} \\
\text { Incremento de la tasa de } \\
\text { impuestos específicos } \\
\text { (bebidas alcohólicas) } \\
\text { Reducción de exoneraciones } \\
\text { y deducciones }\end{array}$ & $\begin{array}{l}\text { Paro empresarial } \\
\text { Recursos de } \\
\text { inconstitucionalidad } \\
\text { Campañas contra el } \\
\text { gobierno en medios de } \\
\text { comunicación } \\
\text { Protestas públicas de } \\
\text { organizaciones sociales }\end{array}$ & $\begin{array}{l}\text { Aprobación de todas las } \\
\text { reformas } \\
\text { Reformas al IEMA, el ISR y } \\
\text { otros impuestos específicos } \\
\text { declarados inconstituciona- } \\
\text { les }\end{array}$ & $\begin{array}{l}1,2 \% \\
\text { (entre 2000 y 2002) } \\
\text { Derogación del IEMA } \\
\text { y otros significó } 1,6 \%\end{array}$ \\
\hline \multicolumn{5}{|c|}{ Casos de negociación de elites } \\
\hline Oscar Berger (2004) & $\begin{array}{l}\text { Reemplazo de impuesto } \\
\text { sobre ventas y activos } \\
\text { Modificaciones al ISR e } \\
\text { impuestos específicos } \\
\text { (bebidas) } \\
\text { Modificaciones al IVA }\end{array}$ & $\begin{array}{l}\text { Negociación } \\
\text { Protestas públicas de } \\
\text { organizaciones sociales por } \\
\text { el IVA e ISR sobre salarios }\end{array}$ & $\begin{array}{l}\text { Aprobación de reforma sin } \\
\text { IVA e ISR sobre salarios } \\
\text { Reducción de tasa y } \\
\text { vigencia de impuesto sobre } \\
\text { venta y activos }\end{array}$ & $\begin{array}{l}\text { Impacto (transitorio) } \\
\text { estimado } 1,0 \%\end{array}$ \\
\hline
\end{tabular}

Fuente: Elaboración propia con datos del Ministerio de Finanzas Públicas.

a IVA: impuesto sobre el valor agregado.

b ISR: impuesto sobre la renta.

c IEMA: impuesto a las empresas mercantiles y agropecuarias.

En síntesis, la suscripción del Pacto Fiscal en el 2000 no dio lugar a un nuevo marco institucional que permitiera efectuar reformas tributarias para consolidar en el país una base impositiva sostenible, con un cumplimiento cuasi voluntario de las obligaciones tributarias. Continuaron dándose procesos de reforma basados en la confrontación, como los que habían predominado en décadas anteriores, o concebidos como una negociación de elites, en parte de carácter cosmético y con poco impacto.

Hay que destacar, sin embargo, dos cambios importantes en la etapa posterior al Pacto Fiscal que podrían facilitar negociaciones futuras. En primer lugar, y a pesar de una política de alianzas amplia y de utilizar todos los recursos necesarios para ejercer su poder de veto, el CACIF no pudo impedir las reformas tributarias impuestas por el gobierno del FRG en los años 2001 y 2002, y el "éxito" de sus recursos de inconstitucionalidad condujeron a la necesidad de una nueva e incompleta reforma tributaria, ahora impulsada por un gobierno favorable al sector empresarial. En otras palabras, el CACIF dejó de tener, al menos transitoriamente, el poder de veto. Además, tanto la posición más débil en que se encontraba como visiones menos rígidas de algunos de sus representantes propiciaron una flexibilización de la postura institucional de esta entidad.

En segundo lugar, y asociado en parte a lo anterior, debe reconocerse un papel incipiente pero cada vez mayor del Congreso en la determinación de la política fiscal del país, así como una participación más marcada de organizaciones sociales en la generación de propuestas y en la fiscalización de la política fiscal. Esto significó que la estrategia de negociación de elites del 2004 tuviera que ampliarse, aunque tardíamente y de manera parcial, para tomar en cuenta a otros actores. 
En suma, no se debe ser pesimista. Tanto la relativa flexibilización de las posiciones del CACIF en el pasado reciente como la mayor participación de organizaciones sociales y del Congreso en torno a la política fiscal, permiten vislumbrar la posibilidad de un futuro marco institucional y de negociación renovado, con una responsabilidad central del Congreso, que podría dar lugar a reformas tributarias concertadas sobre la base de un cumplimiento cuasi voluntario de las obligaciones tributarias de los ciudadanos guatemaltecos en el futuro. Que esto se logre dependerá en buena parte del fortalecimiento de los partidos políticos, sobre todo de aquellos con la capacidad de delinear una visión del Estado a mediano y largo plazo y con la voluntad de impulsarla.

\section{III}

\section{Conclusiones:}

\section{Diez claves de un pacto fiscal exitoso}

Lo anterior tiene diversas implicaciones para acciones futuras en Guatemala o en otros países en torno al tema de la política fiscal. Por una parte, debiera estar clara la diferencia entre una reforma tributaria aislada, a menudo no consolidada social y políticamente, y lo que es un pacto social sobre la política fiscal. Los pactos fiscales normalmente incluyen reformas tributarias de largo alcance que marcan al país y a su política fiscal por mucho tiempo sobre la base de acuerdos cuya negociación se inserta en la institucionalidad democrática del país y que cuentan con un amplio apoyo político y social. ${ }^{22}$ Por otra parte, una vez asegurado un proceso participativo para reformar y reforzar el marco institucional en el cual se define la política fiscal que apunta a garantizar un pacto social efectivo, son las propias experiencias de pactos fiscales en Guatemala y otros países las que sugieren varias recomendaciones:

i) Aprovechar oportunidades de cambios en la correlación de fuerzas internas para impulsar un pacto social sobre la política fiscal.

ii) Contar con una organización o arreglo institucional bien definido para impulsar el proceso y que este tenga credibilidad técnica y política y represente a los principales sectores involucrados en la negociación del pacto social sobre la política fiscal.

iii) Incluir desde el principio a los partidos políticos y al poder legislativo en el proceso de nego-

\footnotetext{
22 Merriam (2004) distingue muy claramente entre ambos aspectos en su análisis del Pacto Fiscal en Guatemala.
}

ciación, tomando en cuenta que el cambio institucional que se busca pretende democratizar la definición de la política fiscal y que ello pasa por incorporar de manera decisiva a los partidos y al poder legislativo como componentes fundamentales de un régimen democrático.

iv) Fundamentar el proceso en un enfoque holístico y de largo plazo, que pueda ampliar el número de temas sujetos a concesiones - sin limitarlo exclusivamente al tema de los impuestos- para facilitar los acuerdos. La negociación de un pacto fiscal no debería ser interpretada como un proceso dirigido a lograr una reforma tributaria de corto plazo, sino como un punto de partida para una reforma duradera del Estado que, basada en un cambio en la correlación de fuerzas, orientará la política pública en el futuro.

v) Definir una estrategia de consultas bien definida y clara que no sólo asegure que se han tomado en cuenta diversos intereses sino que también confiera legitimidad al proceso y permita explicar sus componentes potenciales.

vi) Establecer una relación positiva, de aliados, con los medios de comunicación para que estos apoyen el proceso.

vii) Divulgar la información y los estudios sobre el tema, contribuyendo así a un proceso de aprendizaje colectivo que pueda facilitar la convergencia de posiciones y el desarrollo de un "lenguaje" compartido que permita llegar a acuerdos. Las estadísticas serias y precisas son parte del "lenguaje" que puede favorecer los acuerdos. 
viii) Poner en práctica técnicas de negociación flexibles, tomando en cuenta la experiencia pasada del país en cuestión.

ix) Compensar las asimetrías en la capacidad de negociación de diversos sectores mediante un mayor acceso a la información de los grupos más débiles y el mejoramiento de su capacidad técnica y de negociación.

x) Asignar suficiente tiempo a la construcción de capacidades y a la negociación con el fin de alcanzar los resultados que se esperan.

\section{Bibliografía}

Boylan, D.M. (1996): Taxation and transition: the politics of the 1990 Chilean tax reform, Latin American Research Review, vol. 31, $\mathrm{N}^{\circ} 1$, Pittsburgh, The Latin American Research Association.

CEPAL (Comisión Económica para América Latina y el Caribe) (1996): Economía política de las reformas tributarias en Costa Rica, El Salvador y Guatemala, 1980-1994, LC/MEX/L.294, México, D.F., Sede Subregional de la CEPAL en México.

(1998): El pacto fiscal: fortalezas, debilidades, desafíos, LC/G.1997/Red.1-B, Santiago de Chile. Publicación de las Naciones Unidas, $\mathrm{N}^{\mathrm{o}}$ de venta: S.98.II.G.5.

Comisión Preparatoria del Pacto Fiscal (2000): La política fiscal en Guatemala, Ciudad de Guatemala, Artgrafic.

Easter, G. (2002): Politics of revenue extraction in post-communist states: Poland and Russia compared, Politics and Society, vol. 30, $\mathrm{N}^{\circ}$ 4, Londres, Sage Publications.

Gamboa, N. y B. Tentravizi (2001): La Guatemala posible: la senda del pacto fiscal, Ciudad de Guatemala, Asociación Centroamericana Hombres de Maíz, Oficina de las Naciones Unidas de Servicios para Proyectos/Misión de Verificación de las Naciones Unidas en Guatemala.

Martí, W.J. y R.E. Ortiz (1993): El sector privado y el Estado guatemalteco (1871-1993), Libro No 46, Ciudad de Guatemala, Centro de Estudios Urbanos y Regionales, Universidad de San Carlos (USAC).

McCleary, R. (1999): Imponiendo la democracia: las elites guatemaltecas y el fin del conflicto armado, Ciudad de Guatemala, Librerías Artemis Edinter.

Merriam, R. (2004): The Guatemalan Fiscal Pact: Can It Help Strengthen the Fiscal Social Contract?, Brighton, Institute of Development Studies, Universidad de Sussex.
Noriega, A., E. Alvarez y M. Chocoj (2001): Cuando la sociedad guatemalteca se encuentra: la negociación política del pacto fiscal, Ciudad de Guatemala, Editorial Serviprensa.

Palencia, M. (2002): El Estado para el capital, Ciudad de Guatemala, Facultad Latinoamericana de Ciencias Sociales (FLACSO).

Rosenthal, G. (2005): Conferencia de Gert Rosenthal, en el Instituto Holandés para la Democracia Multipartidaria, Empresariado, política y Estado, Ciclo de conferencias, Ciudad de Guatemala, Magna Terra editores.

Segovia, A. (2004): Modernización empresarial en Guatemala. ¿Cambio real o nuevo discurso?, Ciudad de Guatemala, F y G Editores.

SNU (Sistema de las Naciones Unidas) (2001): Guatemala: el financiamiento del desarrollo humano, Ciudad de Guatemala.

Steinmo, S. (1993): Taxation and Democracy, New Haven, Estados Unidos, Yale University Press.

Urrutia, E. (2000): Ensayo sobre la viabilidad política del pacto fiscal, Colección de educación fiscal, $\mathrm{N}^{\circ} 10$, Ciudad de Guatemala, Facultad Latinoamericana de Ciencias Sociales (FLACSO).

Valdez, F. (2000): La viabilidad de un pacto fiscal en Guatemala: para los empresarios y la sociedad civil, Colección de educación fiscal, $\mathrm{N}^{\circ}$ 6, Ciudad de Guatemala, Facultad Latinoamericana de Ciencias Sociales (FLACSO).

(2003): El ocaso de un liderazgo, Ciudad de Guatemala, Facultad Latinoamericana de Ciencias Sociales (FLACSO).

Valdez, F. y M. Palencia (1998): Los dominios del poder: la encrucijada tributaria, Ciudad de Guatemala, Facultad Latinoamericana de Ciencias Sociales (FLACSO). 